\title{
Thionated Perylene Diimide-Phenothiazine Dyad: Synthesis, Structure, and Electrochemical Studies
}

\author{
Nicholas Pearce, E. Stephen Davies, William Lewis, ${ }^{\circledR}$ and Neil R. Champness*(1) \\ School of Chemistry, University of Nottingham, University Park, Nottingham NG7 2RD, U.K.
}

Supporting Information

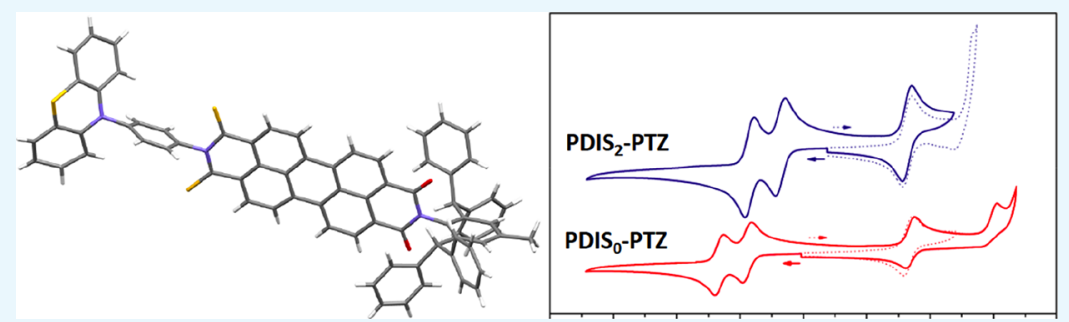

ABSTRACT: Perylene diimides (PDIs) are promising candidates for $\mathrm{n}$-type semiconductor materials and, thus, for use in organic electronics. Thionation of the imide moiety provides an efficient strategy to control the donor-acceptor gap of these types of compounds, although the degree and selectivity of thionation can be hard to achieve. Through the design of a sterically encumbered PDI-phenothiazine dyad, a previously unattained geminal thionation pattern has been realized, providing the first example of a perylene-monoimide-monothioimide. The electrochemical and solid-state structural properties of this uniquely thionated dyad are reported and compared to those of the nonthionated parent molecule. It is found that thionation enhances the electron affinity of the PDI core, affecting electrochemical and spectroelectochemcial behavior of the dyad without significantly affecting the solid-state packing of the molecules.

\section{INTRODUCTION}

Perylene diimides (PDIs) tend to have intense colors, high electron affinities, and excellent photochemical and thermal stabilities. $^{1-3}$ PDIs are excellent candidates for n-type semiconductor materials for organic electronic applications including organic field-effect transistors, ${ }^{4}$ organic light-emitting diodes $^{5,6}$ and dye-sensitized solar cells, ${ }^{7-9}$ and when suitably functionalized can be used as photoelectric materials ${ }^{10}$ and show nonlinear optical properties. ${ }^{11}$

Straightforward synthetic modification of PDIs allows for the tuning of electronic ${ }^{12}$ and photochemical $^{13}$ properties, $^{15}$ solubility $^{1}$ and solid state, ${ }^{14}$ and supramolecular ${ }^{15,16}$ organization. Recently, chalcogen substitutions to the carbonyl positions of the PDI scaffold have been employed as a means of affecting the frontier orbitals without significant perturbation to the molecular structure. Studies into thionated PDIs ${ }^{17-19}$ and their smaller analogues, naphthalene diimides $(\mathrm{NDIs})^{20-26}$ and pyromellitic diimides, ${ }^{27}$ have shown an enhancement in electron mobility in organic transistors, as well as providing a straightforward means of accessing the triplet manifold of PDI without the need for heavy atom substitutions or an additional sensitizer.

Synthetic strategies targeting thionated rylene diimides employ Lawesson's reagent as the source of sulfur atoms and tend to be nonselective, resulting in a series of compounds bearing between one and four substituted carbonyls. ${ }^{17-27}$ In the case of dithionated PDIs and NDIs, three regioisomers are possible with sulfur substituents cis, trans, and geminate to each other, although the current literature contains no reports of isolated geminate thionation products of PDIs. ${ }^{12}$ In the case of NDIs, Welford et al. ${ }^{25}$ were able to isolate a geminately thionated product, albeit in very low yield when compared to the other dithionated isomers. The geminate compound was only one-eighth as prevalent as the cis and trans variants and was produced in lower quantity than the trithionated NDI product, suggesting that thionation usually occurs on opposite imide groups before adjacent imide carbonyls can be substituted.

Recent work has shown that it is possible to selectively produce either $\mathrm{cis}^{20}$ or trans ${ }^{21,22}$ dithionated regioisomers through steric influence of core substituents. Indeed, our earlier work with asymmetric NDI compounds indicated that geminate dithionation can readily occur adjacent to an arylimide substituent, but dithionation next to aliphatic imides is hampered, selectively producing only one of the two possible trithionated regioisomers of a mixed $\mathrm{N}$-aryl/N-alkyl NDI. ${ }^{26}$ Although no similar examples exist for PDI compounds, likely because of the difficulty of controlling levels of orthosubstitution, it is assumed that the principle of sterically selecting which carbonyls can be thionated will hold.

Herein, we describe a steric approach to the synthesis of an unprecedented geminately dithionated PDI-phenothiazine dyad, using a bulky aromatic substituent on one imide terminus of the PDI to limit access to one pair of carbonyls.

Received: September 20, 2018

Accepted: October 16, 2018

Published: October 26, 2018 
Scheme 1. Synthesis of PMI-BDPA and PDI-BDPA

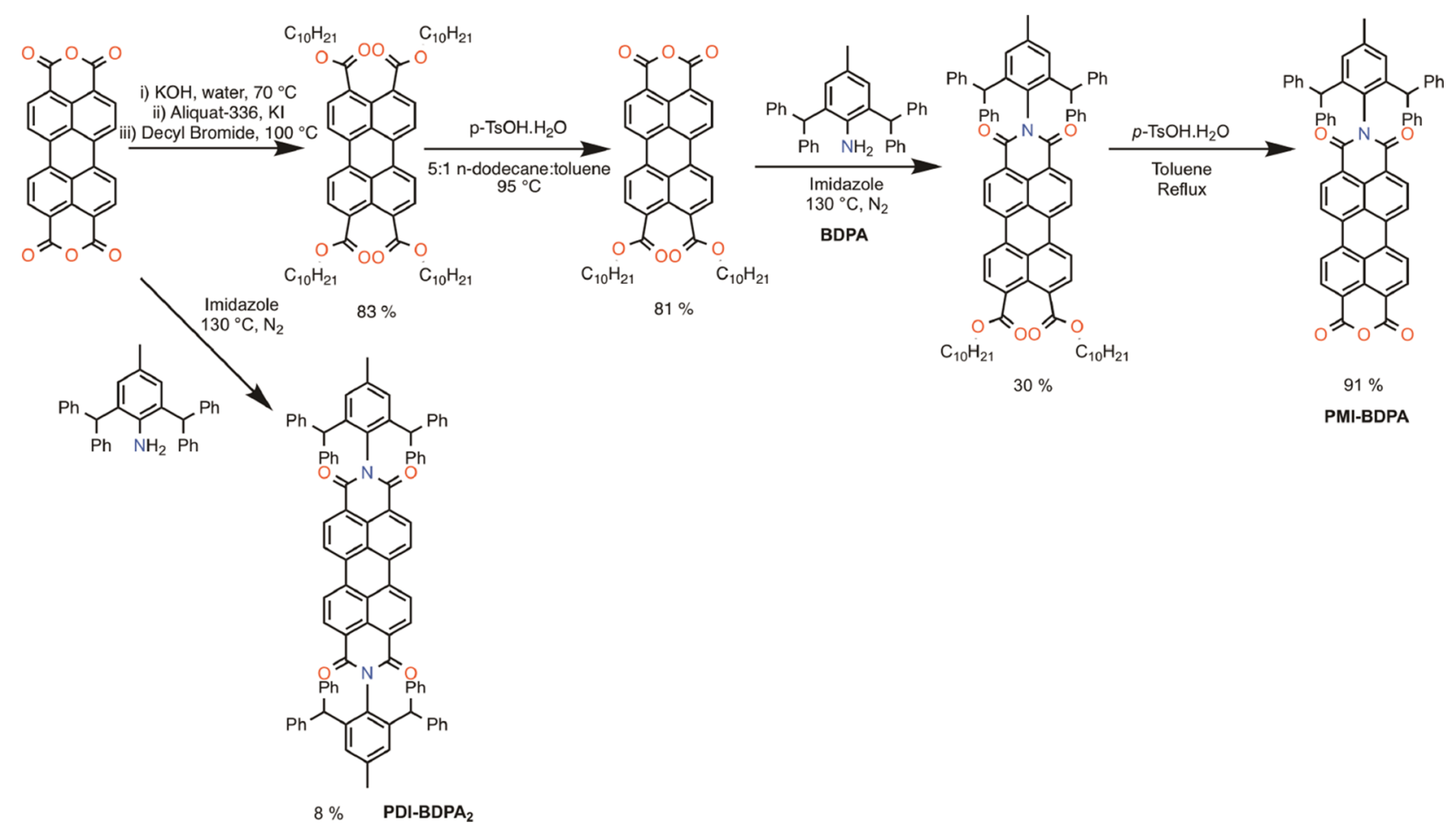

The electrochemical and optical properties of this thionated PDI are compared to those of its nonthionated parent.

\section{RESULTS AND DISCUSSION}

Synthesis and Crystallography of Nonaggregating Asymmetric PDIs. PDIs are often prone to aggregation as a result of intermolecular interactions between their extended aromatic cores, potentially limiting solubility in common organic solvents. In this study, solubility of the target PDIs was essential for characterization and is also desirable for future device fabrication: prohibition of aggregation aides charge separation in donor-acceptor films, ${ }^{28}$ which are commonly produced from spin coating. To this end, we have developed a very sterically hindering tecton, 2,6-(bis)diphenylmethyl-4methylphenyl (BDPA), whose structure is based upon an elaboration of 2,6-diisopropylaniline, a commonly used solubilizing group in PDI chemistry. In this study, the BDPA moiety was used to functionalize one of the imide groups in the synthesis of asymmetric PDIs, providing both steric inhibition to substitution at one imide and solubility for the target molecule.

The synthesis of the PDI-phenothiazine dyad (PDIS $\mathbf{P}_{\mathbf{0}}$-PTZ) followed a synthetic strategy described by Xue et al. ${ }^{29}$ to prepare asymmetric PDIs (Scheme 1). Commercially available perylene-3,4,9,10-dianhydride was first esterified with four $n$ decyl chains. An acid-catalyzed hydrolysis of the resultant tetraester selectively formed a perylene monoanhydride diester which was then condensed with 2,6-(bis)diphenylmethyl-4methylphenylaniline to produce a mixed monoimide diester. The remaining two ester groups were subsequently cleaved giving a perylene-monoimide-monoanhydride (PMI-BDPA) capable of reaction with a second amine, thereby forming an asymmetric PDI. The effectiveness of the 2,6-(bis)diphenylmethyl-4-methylphenyl tecton as a solubilizing group for PDIs is demonstrated upon production of PMI-BDPA, which despite only containing a single imide functionality (and no bay-region substitution) is sufficiently soluble for characterization by ${ }^{13} \mathrm{C}$ NMR spectroscopy.

An X-ray crystallography study of single crystals of PMIBDPA revealed that although $\pi$-stacking is present in the solid state, it is limited to antiparallel pairs of molecules (Figure 1A). The perylene planes of these pairs of molecules are separated by $3.36 \AA$, typical for $\pi$-stacked compounds, ${ }^{30}$ extending to a substantial $6.84 \AA$ between the aromatic cores of adjacent nonstacked molecules. A slight twisting of the perylene plane is also observable: the torsion angle between the two

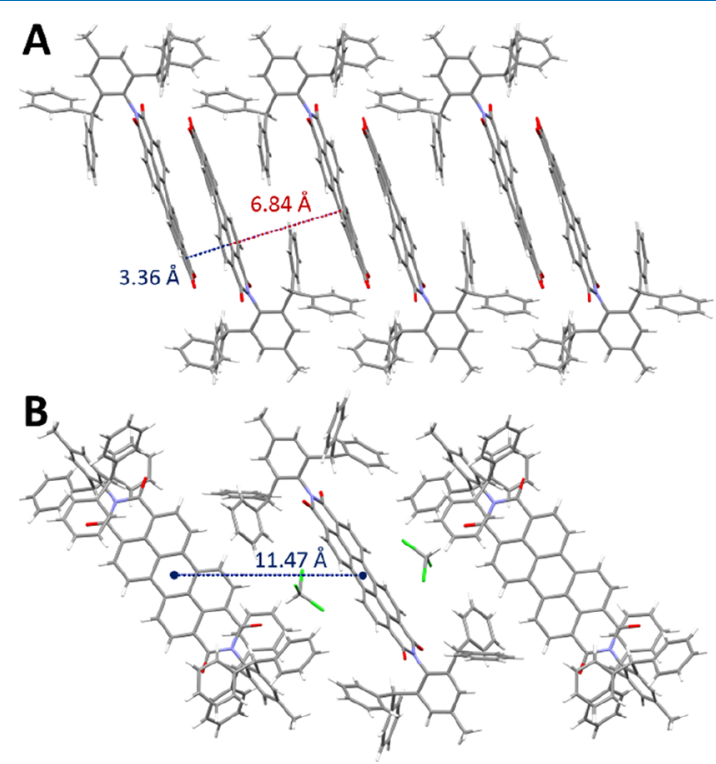

Figure 1. (A) Crystal packing of PMI-BDPA with selected intermolecular distances shown. (B) Crystal packing of PDI-BDPA, showing distance between centroids of adjacent molecules. Atom colors-C: gray, $\mathrm{H}$ : white, $\mathrm{Cl}$ : green, $\mathrm{N}$ : blue, and $\mathrm{O}$ : red. 
Scheme 2. Synthesis of PDI Dyads PDIS $_{0}-\mathrm{PTZ}$ and PDIS $_{2}-\mathrm{PTZ}$

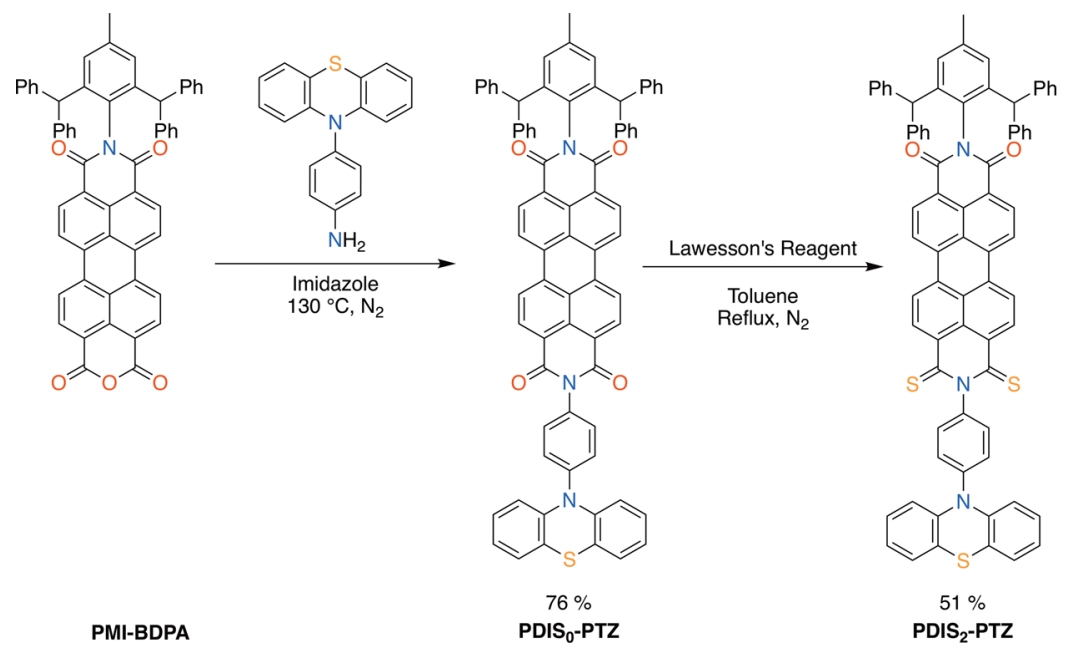

naphthalene rings that comprise a single perylene core is $7.2^{\circ}$. The ability of the bulky 2,6-bis(diphenylmethyl-4-methylphenyl) group to interfere with the $\pi$-stacking normally observed for PDIs is apparent, showcasing the power of this new group for imide functionalization, particularly in asymmetric PDI synthesis, allowing for an unrestricted choice of second imide group without solubility concerns.

In addition to PMI-BDPA, the symmetric diimide analogue with 2,6-(bis)diphenylmethyl-4-methylphenyl substituents at both imide termini, PDI-BDPA 2 , was prepared, and single crystals were grown by vapor diffusion of hexane into a $\mathrm{CHCl}_{3}$ solution of the compound. The compound crystallized in the space group $I 2 / a$, with the asymmetric unit containing half a molecule of PDI-BDPA $\mathbf{A}_{2}$ and two $\mathrm{CHCl}_{3}$ molecules. The imide-substituted phenyl ring lies almost perpendicular to the perylene plane, with an angle between the phenyl plane and the perylene core of $81.1^{\circ}$. The diphenylmethyl branches protrude from the aromatic backbone of the molecule, blocking any potential $\pi-\pi$ interactions. Examination of the intermolecular packing reveals this to be the case: the distance between centroids of adjacent PDI-BDPA $\mathbf{2}_{2}$ molecules is 11.47 $\AA$ (Figure $1 \mathrm{~B}$ ), over three times greater than the typical separation observed for PDIs of $3.40 \AA{ }^{1}$ This represents a huge translational offset and allows solvent $\mathrm{CHCl}_{3}$ molecules to comfortably fit between adjacent PDI molecules. The absence of $\pi-\pi$ interactions extends to solution measurements. The UV/vis spectrum of PDI-BDPA 2 shows $S_{0}$ to $S_{1}$ electronic transitions of the PDI core, with well-defined vibrational structure and relative intensities characteristic of discrete molecules in solution. Furthermore, a solution-phase fluorescence quantum yield of 1.00 for PDI-BDPA 2 is consistent with the absence of aggregation.

Synthesis and Thionation of PDI-Dyads. In line with our previous work using NDIs, ${ }^{26}$ a phenothiazine electron donor group was condensed with PMI-BDPA to produce PDIS $_{0}$-PTZ (Scheme 2). The photophysics of a series of phenylene-spaced phenothiazine-PDI dyads has been investigated by the Wasielewski and co-workers, ${ }^{31}$ noting efficient charge separation between the two chromophores to form a PDI $^{\bullet-}$-Ph-PTZ ${ }^{\bullet+}$ radical pair. Thus, PDIS $_{0}-\mathbf{P T Z}$ was prepared by reaction of PMI-BDPA with 10-(4-aminophenyl)-10- $\mathrm{H}$ phenothiazine. ${ }^{31}$ PDIS $_{0}$-PTZ was thionated with Lawesson's reagent $^{26}$ (Scheme 2) affording a blue compound, in contrast to the red color of PDIS $_{\mathbf{0}}-\mathbf{P T Z}$, that was identified as PDIS $_{2}$ PTZ by mass spectrometry and NMR spectroscopy. The mass spectrum was consistent with two sulfur substitutions, indicating that the product could exist as one of the four isomers. The ${ }^{1} \mathrm{H}$ NMR spectrum of the blue product revealed four pairs of doublets for the aromatic protons of the perylene core (as was the case for the nonthionated PDIS $_{0}$-PTZ) and the ${ }^{13} \mathrm{C}$ NMR spectrum contained only one $\mathrm{C}=\mathrm{O}$ and one $\mathrm{C}=\mathrm{S}$ peak, excluding the possibility of a mixture of cis- or trans-isomers. Thus, both sulfur atoms must be contained within the same imide group, implying a monoimide monothioimide structure. Two such geminately substituted isomers are possible: one with the thioimide located at the phenothiazine terminus and the other with the thioimide at the 2,6-bis(diphenylmethyl-4-methylphenyl) end. NMR spectroscopy implies the former because the protons of the phenylene spacer between the perylene and phenothiazine chromophores are strongly affected by the thionation, splitting from a single peak corresponding to all four phenylene protons of PDIS $_{\mathbf{0}^{-}}$ PTZ to two smaller multiplets for each pair of protons for PDIS $_{2}$-PTZ. No substantial shift was detected for protons of the BDPA group. Additionally, the X-ray crystal structure (see below) of PDIS $_{2}$-PTZ confirms that the thionation occurred at the phenothiazine terminus. This result was expected because of the steric hindrance provided by the aromatic features of the BDPA moiety, and our previous work indicating thionation can readily occur proximal to the phenothiazine-substituted terminus.

Single crystals of suitable quality for X-ray diffraction studies were obtained for both PDIS $_{\mathbf{0}}$-PTZ and PDIS $_{2}-\mathbf{P T Z}$ by vapor diffusion of pentane into a $\mathrm{CHCl}_{3}$ solution of the target compound (Figure 2). Both molecules crystallized in the space

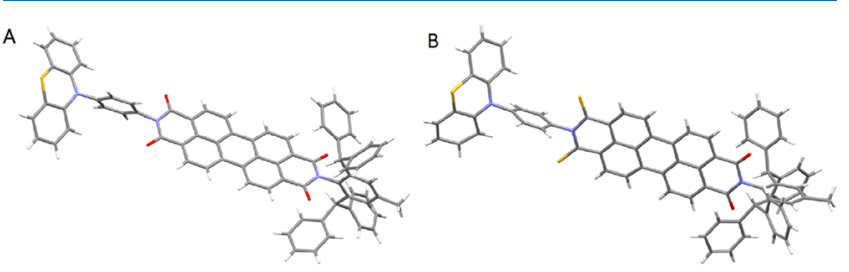

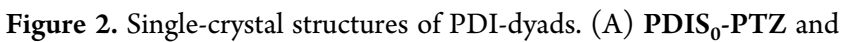
(B) PDIS $_{2}$-PTZ. Atom colors-C: gray, O: red, N: blue, H: white, and S: yellow. 
group $P 2_{1} / c$, with one molecule in the asymmetric unit. Both molecules pack similarly: when viewed along the crystallographic $b$-axis, it can be seen that the phenothiazine group of one molecule lies close to the perylene core of its neighbor (see the Supporting Information for the figure). An additional polymorph of PDIS $_{2}$-PTZ was obtained by slow evaporation from $\mathrm{CHCl}_{3}$ that contains a $\pi$-stacked pair of molecules and two crystallographically resolved $\mathrm{CHCl}_{3}$ molecules, this time in the space group $P 2_{1} / n$. The crystal structure of $\mathbf{P D I S}_{2}-\mathbf{P T Z}$ unambiguously confirms the sulfur substitution positions with the $\mathrm{C}=\mathrm{S}$ bond lengths averaging $1.64 \AA$ versus $1.22 \AA$ for the same two $\mathrm{C}=\mathrm{O}$ bonds of PDIS $_{0}$-PTZ.

Spectroscopy and Electrochemistry. In line with the data from Tilley et al., ${ }^{17}$ the dithionated PDI forms intense blue solutions in $\mathrm{CH}_{2} \mathrm{Cl}_{2}$. PDIS $-\mathrm{PTZ}$, similar to most PDIs without core substitution, is orange in solution but distinguishes itself through a lack of observable fluorescence, signifying that the presence of the phenothiazine chromophore acts to quench fluorescence. In contrast to our previously reported NDI-phenothiazine dyads, ${ }^{26}$ the PDI homologues do not change color from the solution to the solid state. In the $\mathrm{UV} /$ visible spectra, PDIS $_{\mathbf{0}}$-PTZ displays a distinctive band at $\lambda_{\text {max }}=533 \mathrm{~nm}$, resulting from $S_{0}$ to $S_{1}$ electronic transition, with well-defined vibrational structure, the relative intensity of which is indicative of a nonaggregated PDI core in solution. Thionation bathochromically shifts the absorption maximum

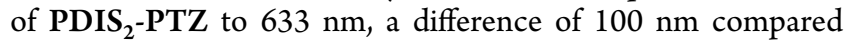
with PDIS $_{0}$-PTZ. Both molecules' spectra display an additional band at $259 \mathrm{~nm}$, attributed to the phenothiazine chromophore (see below for further discussion of $\mathrm{UV} /$ visible spectra of the neutral species).

Both dyads were probed by cyclic voltammetry to investigate their electrochemical behavior. Each compound was found to exhibit two-reversible one-electron reduction processes and one-reversible one-electron oxidation, along with a second oxidation process, that was not reversible under the experimental conditions (Figure 3, Table 1). PDIS $\mathbf{P}_{\mathbf{0}} \mathbf{- P T Z}$ was reduced at -0.94 and $-1.16 \mathrm{~V}$ ( $\mathrm{vs} \mathrm{Fc}^{+} / \mathrm{Fc}$ ), consistent with typical PDIs. ${ }^{32}$ As expected, an anodic shift in the reduction potentials occurred following thionation, ${ }^{19}$ with PDIS $_{2}$-PTZ being reduced at -0.68 and $-0.93 \mathrm{~V}\left(\mathrm{vs} \mathrm{Fc}^{+} / \mathrm{Fc}\right)$.

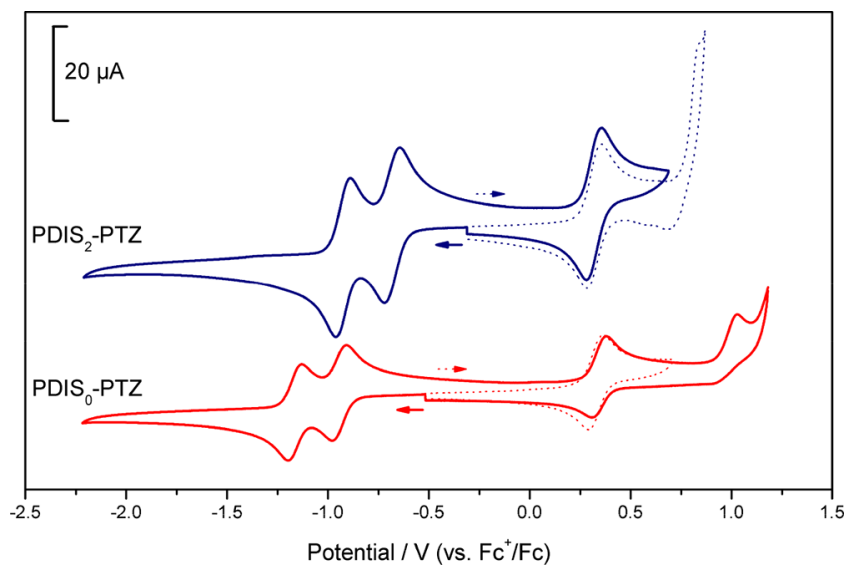

Figure 3. Cyclic voltammograms of PDI-phenothiazine dyads in $\mathrm{CH}_{2} \mathrm{Cl}_{2}$ containing $0.4 \mathrm{M}\left[{ }^{n} \mathrm{Bu}_{4} \mathrm{~N}\right]\left[\mathrm{BF}_{4}\right]$ as the supporting electrolyte, with a scan rate of $100 \mathrm{mV} \mathrm{s}^{-1}$. Red: PDIS $\mathbf{P}_{0}-\mathbf{P T Z}$ and blue: PDIS $_{2}-$ PTZ. Dotted lines represent experiments investigating only the oxidative processes.
Table 1. Redox Potentials of PDI-Phenothiazine Compounds $^{a}$

$\begin{array}{lccc}\text { Compound } & \begin{array}{c}1^{\text {st }} \text { reduction } \\ \mathrm{E}_{1 / 2} / \mathrm{V}\end{array} & \begin{array}{c}2^{\text {nd }} \text { reduction } \\ \mathrm{E}_{1 / 2} / \mathrm{V}\end{array} & \begin{array}{c}1^{\text {st }} \text { oxidation } \\ \mathrm{E}_{1 / 2} / \mathrm{V}\end{array} \\ \text { PDIS }_{0} \text {-PTZ } & -0.94 & -1.16 & 0.33 \\ \text { PDIS }_{2} \text {-PTZ } & -0.68 & -0.93 & 0.32\end{array}$

${ }^{a}$ Potentials quoted against $E_{1 / 2} \mathrm{Fc}^{+} / \mathrm{Fc}$ at $100 \mathrm{mV} \mathrm{s}^{-1}$ used as the internal standard. Recorded in dichloromethane at ambient temperature containing $\left[{ }^{n} \mathrm{Bu}_{4} \mathrm{~N}\right]\left[\mathrm{BF}_{4}\right](0.4 \mathrm{M})$ as the supporting electrolyte.

Although the thionation-induced shift in reduction potential is a substantial $260 \mathrm{mV}$, the effect of thionation is less prominent for the PDI systems than their NDI counterparts (for a comparable pair of NDI-dyads, the reduction potential increased by $360 \mathrm{mV}){ }^{24}$ Thionation lowers the lowest unoccupied molecular orbital (LUMO) energy of the PDI core, improving its power as an electron acceptor. ${ }^{17,18}$ The oxidation potentials for the PDI dyads are 0.33 and $0.32 \mathrm{~V}$ (vs $\mathrm{Fc}^{+} / \mathrm{Fc}$ ) for PDIS $_{0}-\mathbf{P T Z}$ and PDIS $_{2}$-PTZ, respectively, virtually identical to each other and to those of previously reported NDI-phenothiazine. ${ }^{26}$ It is notable that the phenothiazine oxidation is unaffected by thionation of the PDI.

The optical absorbance of PDIS $_{0}$-PTZ and PDIS $\mathbf{P}_{2}$-PTZ was probed using spectroelectrochemical techniques to investigate the change in absorbance profiles upon each reduction and oxidation of the compounds. Upon reduction of PDIS $_{0}-\mathrm{PTZ}$ to $\left[\text { PDIS }_{\mathbf{0}}-\mathbf{P T Z}\right]^{\bullet-}$, the absorbance bands of the neutral species were replaced by intense bands at lower energy (Figure $4)$, consistent with results for other PDIs. ${ }^{12,19,32}$ A similar transformation occurs upon reduction of PDIS $_{2}$-PTZ (Figure 5), although the emergent band at $768 \mathrm{~nm}$ is less structured and more intense $\left(\left[\right.\right.$ PDIS $_{0}$-PTZ $] \lambda_{\max }=716 \mathrm{~nm}, \varepsilon=72800$ $\mathrm{mol}^{-1} \mathrm{dm}^{3} \mathrm{~cm}^{-1}$; and [PDIS - -PTZ] $\lambda_{\text {max }}=768 \mathrm{~nm}, \varepsilon=142$ $\left.100 \mathrm{~mol}^{-1} \mathrm{dm}^{3} \mathrm{~cm}^{-1}\right)$. The progress of reduction from $\left[\text { PDIS }_{0}-\mathrm{PTZ}\right]^{-}$to $\left[\text {PDIS }_{\mathbf{0}}-\mathrm{PTZ}\right]^{2-}$ gave changes in the UV/vis profile that were typical of a PDI, with depletion of the newly formed low-energy bands associated with $\left[\text { PDIS }_{0}-\mathbf{P T Z}\right]^{-}$and an emergence of new peaks for $\left[\right.$ PDIS $_{0}-$ PTZ $^{2-}$ of a similar intensity and energy to those of the neutral compound (Figure 4). A similar result is obtained for the reduction of [PDIS $\mathbf{P}_{2}$ $\mathbf{P T Z}^{\bullet-}$ to $\left[\text { PDIS }_{2}-\mathbf{P T Z}\right]^{2-}$ (Figure 5). Oxidation of the two PDI dyad compounds saw an emergent band at $\sim 515 \mathrm{~nm}$ corresponding to the oxidized phenothiazine chromophore which overlapped with transitions of the PDI core. All process studies were reversible under the conditions of the experiment. See Table 2 for a summary of the UV/visible spectral data.

As mentioned above, PDIS $_{\mathbf{0}}$-PTZ is essentially nonemissive indicating that the normally strong fluorescence associated with a nonaggregated PDI is quenched by the addition of the phenothiazine group. The emission process for a very similar phenothiazine-PDI system, recently reported by Shoer et al., ${ }^{33}$ was also quenched, attributed to complete charge transfer as determined by the results of femtosecond transient absorption spectroscopy. PDIS $_{2}-\mathbf{P T Z}$ is also nonemissive: in addition to the charge-transfer-induced quenching, intersystem crossing to a triplet state is also possible, as reported for thionated PDIs by Tilley et al. ${ }^{17}$

EPR measurements were recorded for the reduced, $\left[\right.$ PDIS $_{0^{-}}$ PTZ $]^{-}$and $\left[\text {PDIS }_{2}-\mathbf{P T Z}\right]^{-}$, and oxidized, $\left[\text {PDIS }_{\mathbf{0}}-\mathbf{P T Z}\right]^{+}$and $\left[\text { PDIS }_{2}-\mathrm{PTZ}\right]^{+}$, dyad species (Figure 6). As expected, the LUMO of the dyads lies on the PDI moiety, evidenced by the complex EPR spectrum for the reduced molecules which 

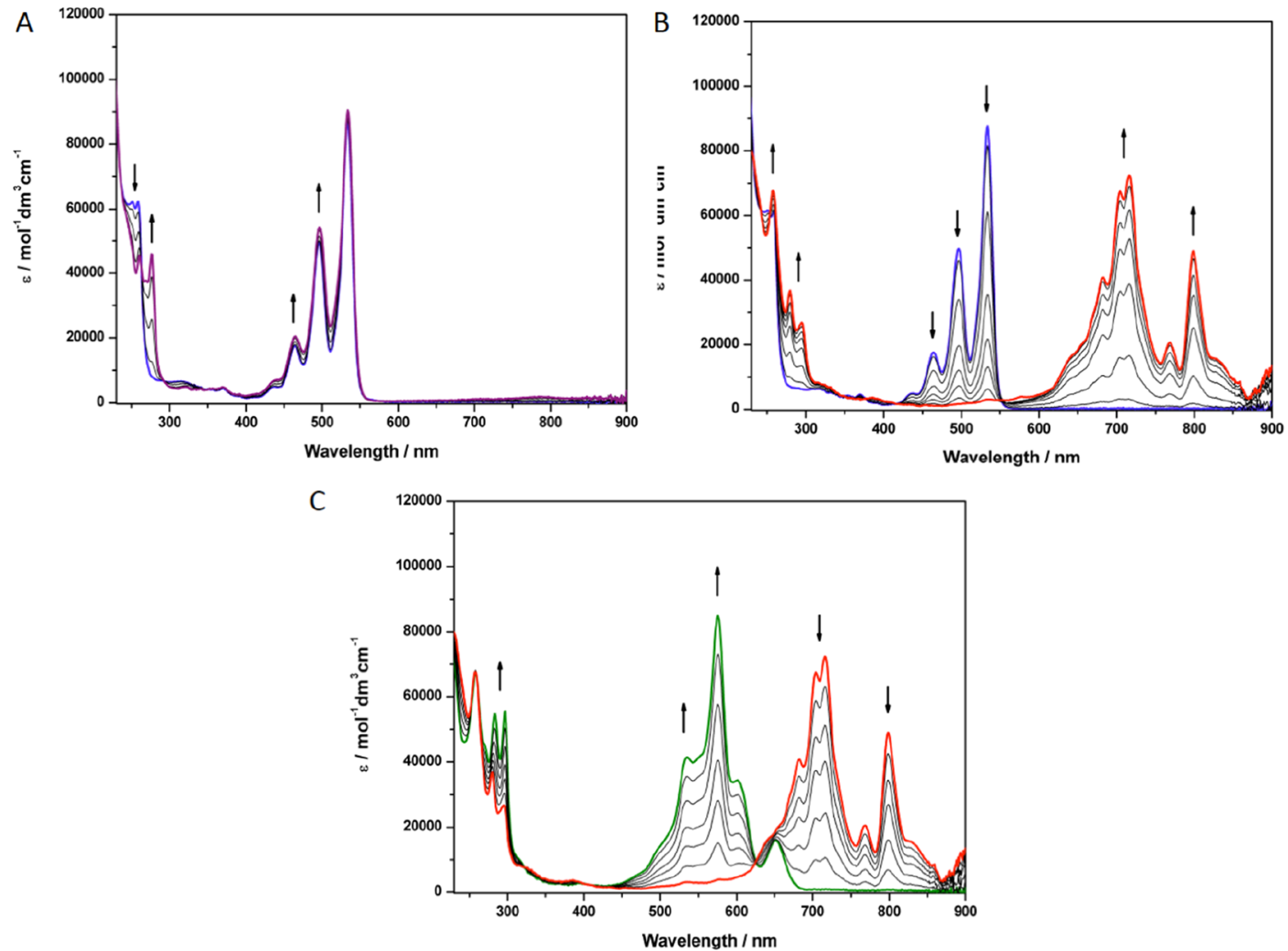

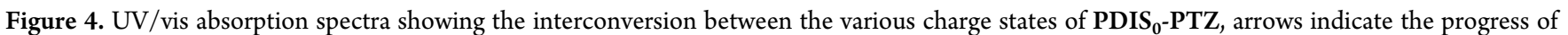
oxidation/reduction. (a) From neutral (blue) to monocationic (purple), (b) from neutral (blue) to monoanionic (red), and (c) from monoanionic (red) to dianionic (green) species. Spectra were recorded in dichloromethane containing $\left[{ }^{n} \mathrm{Bu}_{4} \mathrm{~N}\right]\left[\mathrm{BF}_{4}\right](0.4 \mathrm{M})$ as the supporting electrolyte at $243 \mathrm{~K}$.

signifies coupling of the radical electron to many sets of nonequivalent nuclei (i.e., the four pairs of hydrogen atoms and two nitrogen atoms that comprise the PDI core, where the radical electron is assumed to reside). The molecules' highest occupied molecular orbital (HOMO) is phenothiazine-based with similar EPR spectra recorded for both PDI dyads and analogous to those of our NDI-phenothiazine compounds. ${ }^{26}$ The experimentally determined $g_{\text {iso }}$ values for the two oxidized PDI dyads are identical to each other and to those of the NDI dyads at 2.0055. Such a consistency across this range of molecules is further evidence that the phenothiazine HOMO is fully separated from various acceptor orbitals. The $g_{\text {iso }}$ values

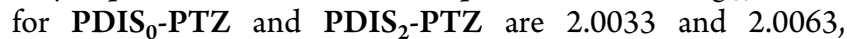
respectively: the increase in value is attributed to the "heavy atom effect" as seen for other thionated molecules discussed. ${ }^{19,26}$

\section{CONCLUSIONS}

Through the introduction of a large aromatic 2,6-bis(diphenylmethyl-4-methylphenyl) moiety that limits $\pi-\pi$ interactions and, thus, aggregation, we have demonstrated that the solubility of PDIs can be greatly improved while still maintaining a rigid conformation. This bulky solubilizing group was used in the synthesis of asymmetric PDI-phenothiazine dyads and enabled solution-phase electrochemical and spectroelectrochemical characterization. The steric encumberment of one terminus of the PDI allows access to an unprecedented geminate sulfur substitution pattern upon thionation with Lawesson's reagent. Cyclic voltammetry revealed that geminate dithionation resulted in a decrease of the HOMO-LUMO gap. Our studies indicate that modification of the frontier orbitals through thionation is readily achieved in PDI-based donor-acceptor dyads, allowing tuning of the HOMO-LUMO energy gap in such systems. It is also evident that the use of steric inhibition of imide groups prohibitsthionation in asymmetric PDI systems facilitating geminate dithionation strategies.

\section{METHODS}

All of the reagents were purchased from commercial suppliers and used without further purification. ${ }^{1} \mathrm{H}$ and ${ }^{13} \mathrm{C}$ NMR spectra were recorded using a Bruker AV(III)400HD spectrometer. MALDI-TOF MS spectra were recorded on a Bruker Ultraflex III spectrometer using trans-2-[3-(4-tertbutylphenyl)-2-methyl-2-propenylidene]-malononitrile as the matrix. EI M/S spectra were taken using a Bruker Apex IV 4.7 $\mathrm{T}$ mass spectrometer. Elemental analyses were recorded on a CE-440 Elemental Analyzer. Standard UV/vis spectra were collected on a PerkinElmer Lambda 25 spectrophotometer using either a 1 or $10 \mathrm{~cm}$ pathlength quartz cuvette. Fluorescence spectra were recorded as aerated solutions using a Jobin Yvon Horiba FluoroMax-3 spectrometer at ambient temperatures in a $1 \mathrm{~cm}$ pathlength quartz cuvette. Quantum yields were calculated in comparison with the fluorescence observed for perylene orange $(\Phi=0.99$ in $\mathrm{CHCl}_{3}$ ) under identical conditions of irradiation. ${ }^{34}$

Electrochemical Measurements. Cyclic voltammetry was carried out using an Autolab PGSTAT20 potentiostat under an argon atmosphere using a three-electrode arrangement in a single compartment cell. Glassy carbon was used as 

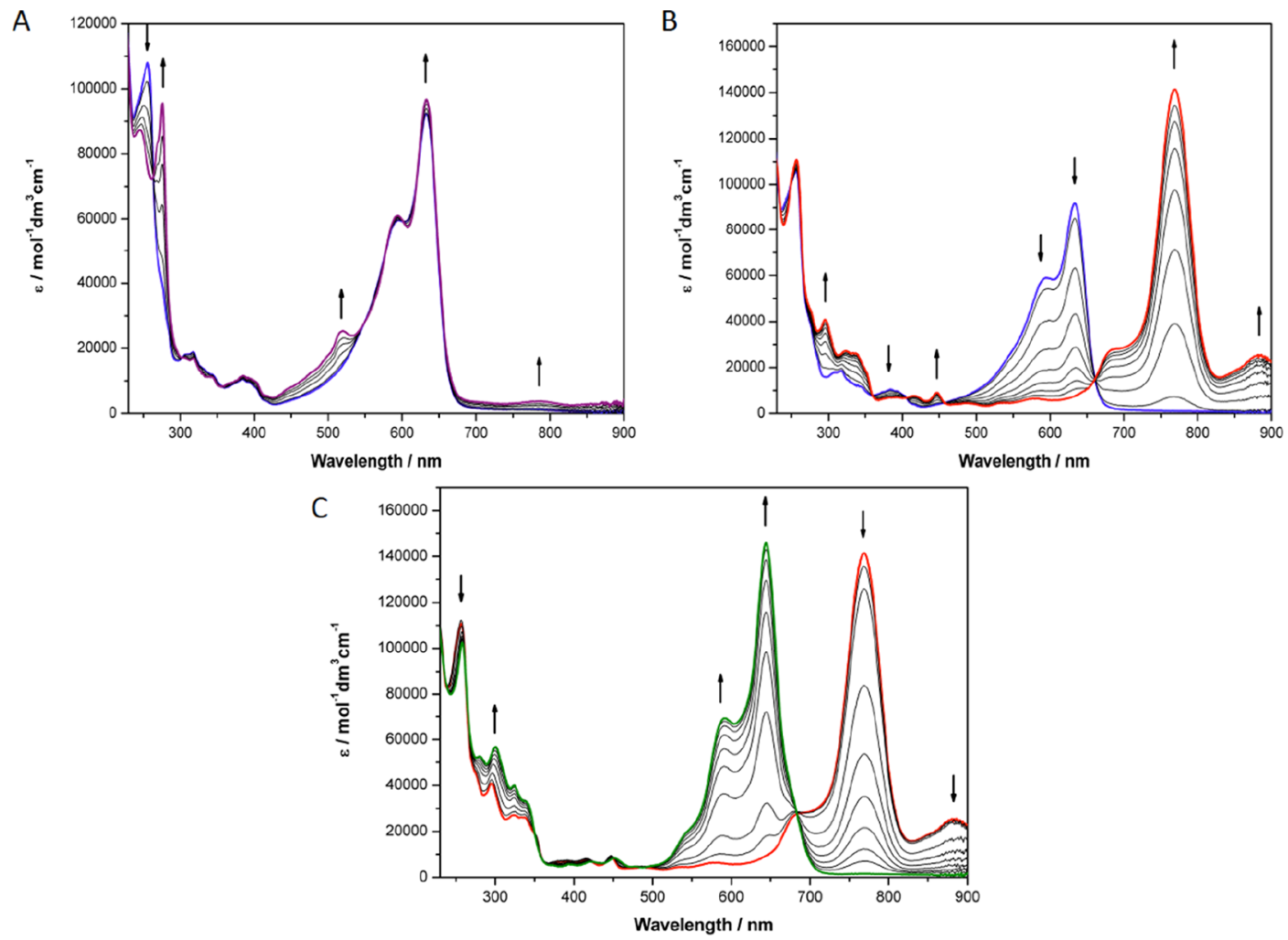

Figure 5. UV/vis absorption spectra showing the interconversion between the various charge states of PDIS $_{2}$-PTZ, arrows indicate the progress of the oxidation/reduction. (a) From neutral (blue) to monocationic (purple), (b) from neutral (blue) to monoanionic (red), (c) from monoanionic (red) to dianionic (green) species. Spectra were recorded in dichloromethane containing $\left[{ }^{n} \mathrm{Bu}_{4} \mathrm{~N}\right]\left[\mathrm{BF}_{4}\right](0.4 \mathrm{M})$ as the supporting electrolyte at $243 \mathrm{~K}$.

Table 2. Summary of Optical Spectroscopy for PDIPhenothiazine Compounds

\begin{tabular}{ccccc}
\hline & \multicolumn{4}{c}{$\lambda_{\text {max }} / \mathrm{nm}\left(\varepsilon / 10^{3} \mathrm{~mol}^{-1} \mathrm{dm}^{3} \mathrm{~cm}^{-1}\right)$} \\
\cline { 2 - 5 } compound & neutral & monoanionic & dianionic & monocationic \\
PDIS -PTZ & $533(88.0)$ & $798(49.1)$ & $652(16.0)$ & $534(90.9)$ \\
& $496(50.1)$ & $768(20.8)$ & $601(34.5)$ & $497(54.7)$ \\
& $465(17.7)$ & $716(72.8)$ & $575(85.1)$ & $464(20.6)$ \\
& $259(61.4)$ & $704(67.4)$ & $535(41.8)$ & $277(46.2)$ \\
& & $681(40.9)$ & $297(55.6)$ & $261(45.5)$ \\
PDIS $_{2}$-PTZ & & $296(26.6)$ & $283(54.7)$ & \\
& & $280(36.8)$ & $258(67.1)$ & \\
& $592(59.5)$ & $768(142.1)$ & $589(69.8)$ & $633(96.9)$ \\
& $318(18.9)$ & $447(9.0)$ & $451(8.7)$ & $593(61.3)$ \\
& $256(106.1)$ & $296(40.8)$ & $325(40.4)$ & $520(25.6)$ \\
& & $257(110.9)$ & $301(57.1)$ & $318(16.9)$ \\
& & & $281(52.7)$ & $277(95.3)$ \\
& & & $259(102.9)$ & $247(87.6)$
\end{tabular}

the working electrode, platinum wire as the secondary electrode, and a saturated calomel reference electrode, chemically isolated from the test solution via a fritted bridge tube containing electrolyte solution, in the cell. An analyte concentration of $1 \mathrm{mM}$ was used with $\left[{ }^{n} \mathrm{Bu}_{4} \mathrm{~N}\right]\left[\mathrm{BF}_{4}\right](400$ $\mathrm{mM}$ ) as the supporting electrolyte. Redox potentials are referenced to the ferrocenium/ferrocene couple, which was implemented as an internal reference. 35 No compensation was applied for the internal resistance.
UV/vis spectroelectrochemical measurements were performed using an optically transparent quartz electrochemical cell, with a $0.5 \mathrm{~mm}$ path length. A three-electrode configuration of a platinum/rhodium gauze working electrode, platinum wire secondary electrode, and a saturated calomel reference electrode (chemically isolated via a fritted bridge tube) were used in the cell. The potential at the working electrode was regulated with a Sycopel Scientific Ltd DD10M potentiostat, and the spectra were recorded with a PerkinElmer 16 spectrophotometer. Temperature control was achieved with a stream of chilled nitrogen gas (cooled by passing through a tube submerged in liquid nitrogen) across the surface of the cell, adjusting the flow rate as necessary in response to a temperature sensor $\left( \pm 0.3{ }^{\circ} \mathrm{C}\right) .\left[{ }^{n} \mathrm{Bu}_{4} \mathrm{~N}\right]\left[\mathrm{BF}_{4}\right](400 \mathrm{mM})$ was used as the supporting electrolyte for the experiments.

Bulk electrolysis was performed under an argon atmosphere at $0{ }^{\circ} \mathrm{C}$ in a two-component cell: a platinum/rhodium gauze working electrode and secondary electrode are separated by a glass frit. A saturated calomel reference was bridged to the test solution through a vycor frit, oriented at the center of the working electrode. The working electrode compartment, containing analyte $(1 \mathrm{mM})$, was stirred rapidly with a magnetic stir bar during electrolysis. $\left[{ }^{n} \mathrm{Bu}_{4} \mathrm{~N}\right]\left[\mathrm{BF}_{4}\right](400 \mathrm{mM})$ was used as the supporting electrolyte for the experiments. After the electrolysis was completed, the prepared solution was transferred by cannula to a Schlenk-adapted quartz EPR tube for analysis at ambient temperature on a Bruker EMX spectrometer at X-band.

Synthesis. Reactions sensitive to air and moisture were performed using a standard Schlenk line, with nitrogen as the inert atmosphere. Glassware used was flame-dried under 

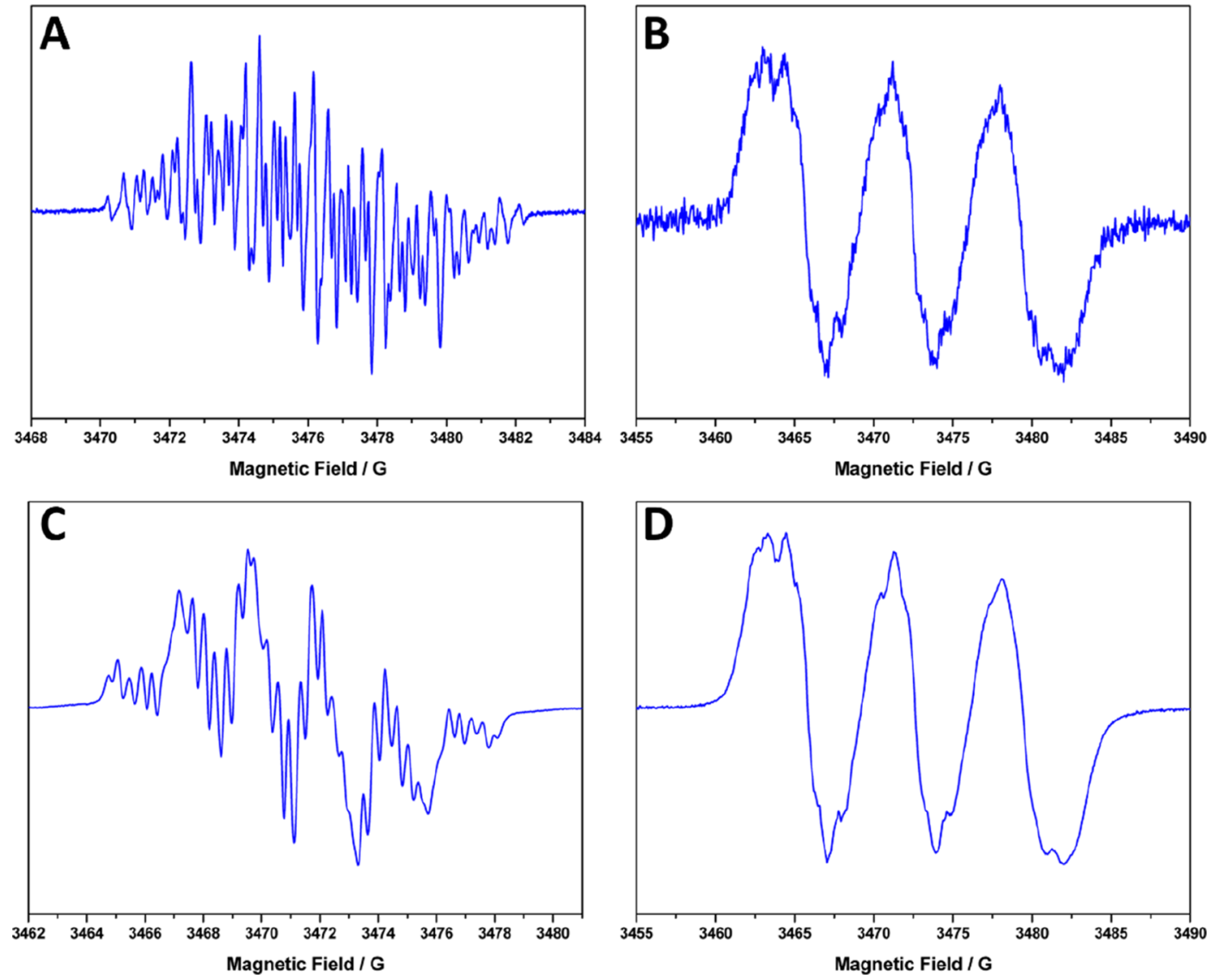

Figure 6. Experimentally measured EPR spectra of PDI-phenothiazine dyads. (A) $\left[\right.$ PDIS $_{0^{-}}$PTZ $^{-}$, (B) $\left[\right.$PDIS $_{0}-$ PTZ $^{+}$, (C) $\left[\right.$PDIS $_{2}-$ PTZ $^{-}$, and (D) $\left[\text { PDIS }_{2} \text {-PTZ }\right]^{+}$.

vacuum and backfilled with nitrogen. Compounds 2,6bis(diphenylmethyl)-4-methylaniline, ${ }^{36}$ 10-(4-aminophenyl)$10 H$-phenothiazine, ${ }^{31}$ 3,4,9,10-tetra(decyloxycarbonyl)perylene, $^{29}$ and perylene-3,4-anhydride-9,10-di(decyloxycarbonyl) ${ }^{27}$ were prepared according to literature methods.

Synthesis of N-(2,6-Bis(diphenylmethyl)-4-methylphenyl)$N^{\prime}$-(10-phenyl-10H-4.4.1.11.phenothiazine)-perylene3,4,9,10-tetracarboxylic Diimide (PDIS - PTZ). A mixture of $N$-(2,6-bis(diphenylmethyl)-4-methylphenyl)-perylene-3,4-dicarboximide-9,10-anhydride (141 mg, $173 \mu \mathrm{mol}$ ), 10-(4aminophenyl)-10H-phenothiazine (70 mg, $243 \mu \mathrm{mol})$, and imidazole $(5.00 \mathrm{~g}, 73.4 \mathrm{mmol})$ were heated to $130{ }^{\circ} \mathrm{C}$ under dinitrogen for $3 \mathrm{~h}$. The reaction was then cooled to $100{ }^{\circ} \mathrm{C}$, and then hydrochloric acid $(50 \mathrm{~mL}, 2 \mathrm{M})$ was added. After 10 min, the reaction mixture was allowed to cool to room temperature and extracted with $\mathrm{CHCl}_{3}(2 \times 100 \mathrm{~mL})$. The combined organics were washed with hydrochloric acid (100 $\mathrm{mL})$, water $(100 \mathrm{~mL})$, and brine $(100 \mathrm{~mL})$ and dried over $\mathrm{MgSO}_{4}$. The orange solution was concentrated under reduced pressure, and the crude product was purified by column chromatography (silica, 99:1 chloroform/acetone) to give the product as a red solid $\left(140 \mathrm{mg}, 76 \%, \mathrm{mp}=276^{\circ} \mathrm{C}\right) \cdot \lambda_{\max }(\mathrm{abs})$ $=530 \mathrm{~nm}$. Fluorescence quantum yield $\Phi_{\mathrm{f}}<0.01 .{ }^{1} \mathrm{H}$ NMR $\left(400 \mathrm{MHz}, \mathrm{CDCl}_{3}\right): \delta$ ppm $8.81(\mathrm{~d}, J=8.0 \mathrm{~Hz}, 2 \mathrm{H}), 8.74(\mathrm{~d}, J$ $=8.2 \mathrm{~Hz}, 2 \mathrm{H}), 8.64(\mathrm{~d}, J=8.2 \mathrm{~Hz}, 2 \mathrm{H}), 8.38(\mathrm{~d}, J=8.0 \mathrm{~Hz}$, $2 \mathrm{H}), 7.57(\mathrm{~s}, 4 \mathrm{H}), 7.17-7.09(\mathrm{~m}, 14 \mathrm{H}), 7.04-6.96(\mathrm{~m}, 10 \mathrm{H})$, $6.91(\mathrm{dt}, J=1.3,7.4 \mathrm{~Hz}, 2 \mathrm{H}), 6.79(\mathrm{~s}, 2 \mathrm{H}), 6.53(\mathrm{dd}, J=1.1$, $8.2 \mathrm{~Hz}, 2 \mathrm{H}), 5.35$ (s, 2H), 2.25 (s, 3H). ${ }^{13} \mathrm{C} \mathrm{NMR} \mathrm{(125} \mathrm{MHz,}$ $\left.\mathrm{CDCl}_{3}\right): \delta \mathrm{ppm} 163.63,162.24,143.76,142.20,142.11$,
$141.89,138.10,135.53,134.43,133.90,132.02,131.35,131.28$, $130.98,130.00,129.93,129.64,129.55,129.49,128.14,127.05$, $127.01,126.84,126.49,126.27,123.55,123.29,123.20,123.13$, $123.07,121.91,117.58,52.60,21.78$. IR (ATR): 3056, 3022, $1702,1665,1592,1576,1340 \mathrm{~cm}^{-1}$. HRMS (MALDI) ${ }^{+} \mathrm{m} / z$ : $1085.3298\left(\mathrm{C}_{75} \mathrm{H}_{47} \mathrm{~N}_{3} \mathrm{O}_{4} \mathrm{~S}_{1}[\mathrm{M}]^{+}\right.$requires, 1085.3282).

Synthesis of $\mathrm{N}$-(2,6-Bis(diphenylmethyl)-4-methylphenyl)$N^{\prime}$-(10-phenyl-10H-4.4.1.12.phenothiazine)-perylene-3,4imide-9,10-dithioimide (PDIS ${ }_{2}$-PTZ). PDIS ${ }_{0}$-PTZ (140 mg, $129 \mu \mathrm{mol})$ and Lawesson's reagent $(261 \mathrm{mg}, 645 \mu \mathrm{mol})$ were dissolved in anhydrous toluene $(25 \mathrm{~mL})$ and heated to reflux for $20 \mathrm{~h}$. The solution was cooled to room temperature and washed with sat. aq $\mathrm{NaHCO}_{3}(100 \mathrm{~mL})$, water $(100 \mathrm{~mL})$, and sat. aq $\mathrm{NaCl}(100 \mathrm{~mL})$; dried over $\mathrm{MgSO}_{4}$; filtered; and the solvent removed to give a blue solid. The product was purified by column chromatography (silica, gradient elution from chloroform to 19:1 chloroform/acetone) to give PDIS $_{2}-\mathrm{PTZ}$ as a blue microcrystalline powder $\left(73 \mathrm{mg}, 51 \%, \mathrm{mp}=277^{\circ} \mathrm{C}\right)$. $\lambda_{\max }(\mathrm{abs})=633 \mathrm{~nm} .{ }^{1} \mathrm{H} \mathrm{NMR}\left(400 \mathrm{MHz}, \mathrm{CDCl}_{3}\right): \delta \mathrm{ppm}$ $9.03(\mathrm{~d}, J=8.4 \mathrm{~Hz}, 2 \mathrm{H}), 8.61(\mathrm{~d}, J=8.2 \mathrm{~Hz}, 2 \mathrm{H}), 8.56(\mathrm{~d}, J=$ $8.7 \mathrm{~Hz}, 2 \mathrm{H}), 8.37(\mathrm{~d}, J=8.0 \mathrm{~Hz}, 2 \mathrm{H}), 7.57-7.50(\mathrm{~m}, 2 \mathrm{H})$, 7.43-7.37 (m, 2H), 7.19-7.09 (m, 14H), 7.06-6.98 (m, $10 \mathrm{H}), 6.91(\mathrm{dt}, J=1.1,7.4 \mathrm{~Hz}, 2 \mathrm{H}), 6.80(\mathrm{~s}, 2 \mathrm{H}), 6.58(\mathrm{dd}, J=$ $1.1,8.2 \mathrm{~Hz}, 2 \mathrm{H}), 5.37$ (s, 2H), $2.26(\mathrm{~s}, 3 \mathrm{H}) .{ }^{13} \mathrm{C} \mathrm{NMR}(100$ $\left.\mathrm{MHz}, \mathrm{CDCl}_{3}\right): \delta$ ppm 190.18, 162.29, 144.43, 143.70, 142.19, $142.14,141.18$, 138.10, 137.46, 137.41, 134.72, 134.12, 131.42, $131.30,130.68,130.28,129.66,129.61,129.57,129.50,128.15$, 127.08, 127.01, 126.53, 126.29, 126.12, 124.95, 123.52, 123.48, 123.06, 121.93, 117.59, 52.59, 21.79. IR (ATR): 3056, 3021, 
1706, 1665, 1588, 1567, 1220, $1163 \mathrm{~cm}^{-1}$. HRMS (MALDI) ${ }^{+}$ $m / z: 1117.2822\left(\mathrm{C}_{75} \mathrm{H}_{47} \mathrm{~N}_{3} \mathrm{O}_{2} \mathrm{~S}_{3}[\mathrm{M}]^{+}\right.$requires, 1117.2825).

\section{ASSOCIATED CONTENT}

\section{S Supporting Information}

The Supporting Information is available free of charge on the ACS Publications website at DOI: 10.1021/acsomega.8b02457.

Full synthetic details, additional crystallographic data; CCDC 1868841, (PMI-BDPA), CCDC 1868842,

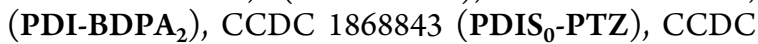
1868844, (PDIS 2 -PTZ), and CCDC 1868845 (PDIS $_{2}$ PTZ polymorph 2) (PDF)

\section{AUTHOR INFORMATION}

\section{Corresponding Author}

*E-mail: Neil.Champness@nottingham.ac.uk. Phone: +44 (0) 1159513505 (N.R.C.).

ORCID $\odot$

William Lewis: 0000-0001-7103-6981

Neil R. Champness: 0000-0003-2970-1487

Notes

The authors declare no competing financial interest.

\section{ACKNOWLEDGMENTS}

We thank the Engineering and Physical Sciences Research Council (EP/N033906/1) for support.

\section{REFERENCES}

(1) Würthner, F.; Saha-Möller, C. R.; Fimmel, B.; Ogi, S.; Leowanawat, P.; Schmidt, D. Perylene Bisimide Dye Assemblies as Archetype Functional Supramolecular Materials. Chem. Rev. 2016, 116, 962-1052.

(2) Chen, Z.; Baumeister, U.; Tschierske, C.; Würthner, F. Effect of Core Twisting on Self-Assembly and Optical Properties of Perylene Bisimide Dyes in Solution and Columnar Liquid Crystalline Phases. Chem.-Eur. J. 2007, 13, 450-465.

(3) Seybold, G.; Wagenblast, G. New perylene and violanthrone dyestuffs for fluorescent collectors. Dyes Pigm. 1989, 11, 303-317.

(4) Zhan, X.; Facchetti, A.; Barlow, S.; Marks, T. J.; Ratner, M. A.; Wasielewski, M. R.; Marder, S. R. Rylene and Related Diimides for Organic Electronics. Adv. Mater. 2011, 23, 268-284.

(5) Hwang, S.-H.; Moorefield, C. N.; Newkome, G. R. Dendritic macromolecules for organic light-emitting diodes. Chem. Soc. Rev. 2008, 37, 2543-2557.

(6) Erten, S.; Meghdadi, F.; Gunes, S.; Koeppe, R.; Sariciftci, N. S.; Icli, S. Donor-acceptor heterojunction solar cells based on perylene dimide and perylene bisbenzimidazole. Eur. Phys. J.: Appl. Phys. 2006, $36,225-229$.

(7) Ferrere, S.; Zaban, A.; Gregg, B. A. Dye Sensitization of Nanocrystalline Tin Oxide by Perylene Derivatives. J. Phys. Chem. B 1997, 101, 4490-4493.

(8) Tian, H.; Liu, P.-H.; Zhu, W.; Gao, E.; Wu, D.-J.; Cai, S. Synthesis of novel multi-chromophoric soluble perylene derivatives and their photosensitizing properties with wide spectral response for $\mathrm{SnO}_{2}$ nanoporous electrode. J. Mater. Chem. 2000, 10, 2708-2715.

(9) Cao, J.; Sun, J.-Z.; Hong, J.; Yang, X.-G.; Chen, H.-Z.; Wang, M. Direct observation of microscopic photoinduced charge redistribution on $\mathrm{TiO}_{2}$ film sensitized by chloroaluminum phthalocyanine and perylenediimide. Appl. Phys. Lett. 2003, 83, 1896-1898.

(10) Liang, X.; Zhang, Q. Recent progress on intramolecular chargetransfer compounds as photoelectric active materials. Sci. China Mater. 2017, 60, 1093-1101.

(11) Cao, L.; Xu, L.; Zhang, D.; Zhou, Y.; Zheng, Y.; Fu, Q.; Jiang, X.-F.; Lu, F. D-A dyad and D-A-D triad incorporating triphenylamine, benzanthrone and perylene diimide: Synthesis, electrochemical, linear and nonlinear optical properties. Chem. Phys. Lett. 2017, 682, 133139.

(12) Goretzki, G.; Davies, E. S.; Argent, S. P.; Alsindi, W. Z.; Blake, A. J.; Warren, J. E.; McMaster, J.; Champness, N. R. Bis-morpholineSubstituted Perylene Bisimides: Impact of Isomeric Arrangement on Electrochemical and Spectroelectrochemical Properties. J. Org. Chem. 2008, 73, 8808-8814.

(13) Wang, K.-R.; Yang, Z.-B.; Li, X.-L. High Excimer-State Emission of Perylene Bisimides and Recognition of Latent Fingerprints. Chem.-Eur. J. 2015, 21, 5680-5684.

(14) Haddow, S. L.; Ring, D. J.; Bagha, H.; Pearce, N.; Nowell, H.; Blake, A. J.; Lewis, W.; McMaster, J.; Champness, N. R. Perylene Diimide Triple Helix Formation in the Solid State. Cryst. Growth Des. 2018, 18, 802-807.

(15) Draper, E. R.; Greeves, B. J.; Barrow, M.; Schweins, R.; Zwijnenburg, M. A.; Adams, D. J. pH-directed aggregation to control photoconductivity in self-assembled perylene bisimides. Chem 2017, $2,716-731$.

(16) Slater, A. G.; Perdigão, L. M. A.; Beton, P. H.; Champness, N. R. Surface-Based Supramolecular Chemistry Using Hydrogen Bonds. Acc. Chem. Res. 2014, 47, 3417-3427.

(17) Tilley, A. J.; Pensack, R. D.; Lee, T. S.; Djukic, B.; Scholes, G. D.; Seferos, D. S. Ultrafast Triplet Formation in Thionated Perylene Diimides. J. Phys. Chem. C 2014, 118, 9996-10004.

(18) Tilley, A. J.; Guo, C.; Miltenburg, M. B.; Schon, T. B.; Yan, H.; Li, Y.; Seferos, D. S. Thionation Enhances the Electron Mobility of Perylene Diimide for High Performance n-Channel Organic Field Effect Transistors. Adv. Funct. Mater. 2015, 25, 3321-3329.

(19) Llewellyn, B. A.; Davies, E. S.; Pfeiffer, C. R.; Cooper, M.; Lewis, W.; Champness, N. R. Thionated Perylene Diimides with Intense Absorbance in the Near-IR. Chem. Commun. 2016, 52, 20992102.

(20) Chen, W.; Zhang, J.; Long, G.; Liu, Y.; Zhang, Q. From nondetectable to decent: replacement of oxygen with sulfur in naphthalene diimide boosts electron transport in organic thin-film transistors (OTFT). J. Mater. Chem. C 2015, 3, 8219-8224.

(21) Etheridge, F. S.; Fernando, R.; Golen, J. A.; Rheingold, A. L.; Sauve, G. Tuning the optoelectronic properties of core-substituted naphthalene diimides by the selective conversion of imides to monothioimides. RSC Adv. 2015, 5, 46534-46539.

(22) Pahlavanlu, P.; Tilley, A. J.; McAllister, B. T.; Seferos, D. S. Microwave Synthesis of Thionated Naphthalene Diimide-Based Small Molecules and Polymers. J. Org. Chem. 2017, 82, 12337-12345.

(23) Kozycz, L. M.; Guo, C.; Manion, J. G.; Tilley, A. J.; Lough, A. J.; Li, Y.; Seferos, D. S. Enhanced electron mobility in crystalline thionated naphthalene diimides. J. Mater. Chem. C 2015, 3, 1150511515.

(24) Chen, W.; Nakano, M.; Takimiya, K.; Zhang, Q. Selective thionation of naphtho[2,3-b]thiophene diimide: tuning of the optoelectronic properties and packing structure. Org. Chem. Front. 2017, 4, 704-710.

(25) Welford, A.; Maniam, S.; Gann, E.; Thomsen, L.; Langford, S. J.; McNeill, C. R. Thionation of naphthalene diimide molecules: Thin-film microstructure and transistor performance. Org. Electron. 2018, 53, 287-295.

(26) Pearce, N.; Davies, E. S.; Horvath, R.; Pfeiffer, C. R.; Sun, X.-Z.; Lewis, W.; McMaster, J.; George, M. W.; Champness, N. R. Thionated Naphthalene Diimides: Tuneable Chromophores for Applications in Photoactive Dyads. Phys. Chem. Chem. Phys. 2018, 20, $752-764$

(27) Yang, T.-F.; Huang, S.-H.; Chiu, Y.-P.; Chen, B.-H.; Shih, Y.W.; Chang, Y.-C.; Yao, J.-Y.; Lee, Y.-J.; Kuo, M.-Y. Pyromellitic dithioimides: thionation improves air-stability and electron mobility of N-type organic field-effect transistors. Chem. Commun. 2015, 51, 13772-13775.

(28) Ramanan, C.; Smeigh, A. L.; Anthony, J. E.; Marks, T. J.; Wasielewski, M. R. Competition between Singlet Fission and Charge Separation in Solution-Processed Blend Films of 6,13-Bis- 
(triisopropylsilylethynyl)pentacene with Sterically-Encumbered Perylene-3,4:9,10-bis(dicarboximide)s. J. Am. Chem. Soc. 2012, 134, 386-397.

(29) Xue, C.; Sun, R.; Annab, R.; Abadi, D.; Jin, S. Perylene monoanhydride diester: a versatile intermediate for the synthesis of unsymmetrically substituted perylene tetracarboxylic derivatives. Tetrahedron Lett. 2009, 50, 853-856.

(30) Hunter, C. A.; Sanders, J. K. M. The nature of $\pi-\pi$ interactions. J. Am. Chem. Soc. 1990, 112, 5525-5534.

(31) Weiss, E. A.; Ahrens, M. J.; Sinks, L. E.; Gusev, A. V.; Ratner, M. A.; Wasielewski, M. R. Making a Molecular Wire: Charge and Spin Transport through para-Phenylene Oligomers. J. Am. Chem. Soc. 2004, 126, 5577-5584.

(32) Slater, A. G.; Davies, E. S.; Argent, S. P.; Lewis, W.; Blake, A. J.; McMaster, J.; Champness, N. R. Bis-thioether-Substituted Perylene Diimides: Structural, Electrochemical, and Spectroelectrochemical Properties. J. Org. Chem. 2013, 78, 2853-2862.

(33) Shoer, L. E.; Eaton, S. W.; Margulies, E. A.; Wasielewski, M. R. Photoinduced Electron Transfer in 2,5,8,11-Tetrakis-Donor-Substituted Perylene-3,4:9,10-bis(dicarboximides). J. Phys. Chem. B 2015, 119, 7635-7643.

(34) Brouwer, A. M. Standards for photoluminescence quantum yield measurements in solution (IUPAC Technical Report). Pure Appl. Chem. 2011, 83, 2213-2228.

(35) Gagne, R. R.; Koval, C. A.; Lisensky, G. C. Ferrocene as an internal standard for electrochemical measurements. Inorg. Chem. 1980, 19, 2854-2855.

(36) Berthon-Gelloz, G.; Siegler, M. A.; Spek, A. L.; Tinant, B.; Reek, J. N. H.; Markó, I. E. IPr* an easily accessible highly hindered N-heterocyclic carbene. Dalton Trans. 2010, 39, 1444-1446. 